


\title{
Human sepsis-associated Escherichia coli (SEPEC) is able to adhere to and invade kidney epithelial cells in culture
}

\author{
R.A. Conceição ${ }^{1}$, M.S. Ludovico², C.G.T.J. Andrade ${ }^{3}$ and T. Yano ${ }^{1}$ \\ ${ }^{1}$ Departamento de Genética, Evolução e Bioagentes, \\ Universidade Estadual de Campinas, Campinas, SP, Brasil \\ 2Departamento de Microbiologia, Universidade Estadual de Londrina, Londrina, PR, Brasil \\ ${ }^{3}$ Departamento de Biologia Geral, Universidade Estadual de Londrina, Londrina, PR, Brasil
}

\begin{abstract}
The adhesins of extraintestinal pathogenic Escherichia coli are essential for mediating direct interactions between the microbes and the host cell surfaces that they infect. Using fluorescence microscopy and gentamycin protection assays, we observed that 49 sepsis-associated E. coli (SEPEC) strains isolated from human adults adhered to and invaded Vero cells in the presence of D-mannose (100\%). In addition, bacteria concentrations of approximately $2 \times 10^{7} \mathrm{CFU} / \mathrm{mL}$ were recovered from Vero cells following an invasion assay. Furthermore, PCR analysis of adhesin genes showed that $98.0 \%$ of these SEPEC strains tested positive for $f i m \mathrm{H}, 69.4 \%$ for flu, 53.1\% for csgA, 38.8\% for mat, and $32.7 \%$ for iha. Analysis of the invasin genes showed that $16.3 \%$ of the SEPEC strains were positive for tia, $12.3 \%$ for gimB, and $10.2 \%$ for ibeA. Therefore, these data suggest that SEPEC adhesion to cell surfaces occurs through non-fim $\mathrm{H}$ mechanisms. Scanning electron microscopy showed the formation of microcolonies on the Vero cell surface. SEPEC invasiveness was also confirmed by the presence of intracellular bacteria, and ultrastructural analysis using electron transmission microscopy revealed bacteria inside the Vero cells. Taken together, these results demonstrate that these SEPEC strains had the ability to adhere to and invade Vero cells. Moreover, these data support the theory that renal cells may be the predominant pathway through which SEPEC enters human blood vessels.
\end{abstract}

Key words: Adhesion; Invasiveness; Escherichia coli; Sepsis

\section{Introduction}

Escherichia coli bacteria are commonly described as the major causative agent of extraintestinal infections, such as neonatal meningitis, bacteremia, pyelonephritis, cystitis, prostatitis, and sepsis (1-4). Paradoxically, this microorganism is also a predominant facultative member of the normal human intestinal microbiota $(5,6)$. The adhesion of pathogenic bacteria to host cells represents the first step in establishing an infection. Subsequent events include the colonization of tissues and, in certain cases, cellular invasion followed by intracellular multiplication or persistence. The adhesion process is initiated when surface structures known as adhesins bind to their specific ligands, host cell receptors or extracellular matrix proteins $(4,7)$.

Although the occurrence of $E$. coli bacteremia and sepsis has increased in recent years $(3,8)$, there are few reports detailing the mechanisms of sepsis-associated $E$. coli (SEPEC) pathogenesis. Furthermore, it is possible that the virulence genotypes and phylogenetic backgrounds of E. coli strains differ in diverse geographical regions (9). Recently, a study on the genetic profile of SEPEC strains reported heterogeneity in previously described extraintestinal pathogenic E. coli (ExPEC) virulence factors (10).

The contamination by ExPEC strains is usually related to the contamination of urinary or other catheters $(3,11)$. The urinary tract is the main gateway for ExPEC, particularly in cases of sepsis (4). Urinary infections often provoke bacteremia, especially in patients that are hospitalized because of catheter contamination by ExPEC biofilms (3). ExPEC strains, such as uropathogenic E. coli (UPEC), neonatal meningitis-associated E. coli (NMEC), and SEPEC, typically share many virulence factors that promote the colonization of host surfaces, avoidance and/or subversion of

Correspondence: T. Yano, Departamento de Genética, Evolução e Bioagentes, UNICAMP, Caixa postal 6109, 13081-970 Campinas, SP, Brasil. Fax: +55-3521-6276. E-mail: tyano@unicamp.br

Received August 26, 2011. Accepted March 29, 2012. Available online April 13, 2012. Published May 7, 2012. 
host defense mechanisms, invasion and/or injury of cells and tissues and the initiation of inflammatory responses $(4,9,12)$. In this study, we evaluated the presence of five adhesin-encoding genes ( $f i m \mathrm{H}, f l u, c s g \mathrm{~A}$, mat, and iha) and three invasin-encoding genes (ibeA, tia and $\operatorname{gim} \mathrm{B}$ ) in 49 E. coli isolates from human sepsis patients and also investigated the adhesive and invasive abilities of these isolates in Vero cells.

\section{Material and Methods}

\section{Bacterial strains}

We analyzed a collection of 49 previously described SEPEC strains (10) maintained in our laboratories as stocks at room temperature. All strains were screened for the presence of adhesin/invasin-encoding genes and qualitatively assayed for their adhesion to and invasion of Vero cells. Based on these data, we selected four strains for further analysis using scanning (SEM) and transmission electron microscopy (TEM).

\section{Genotyping characterization}

Molecular analysis assays. PCR amplifications were performed in a final reaction volume of $30 \mu \mathrm{L}$. The primers used for the analyses were selected from previously published sequences: i) adhesins: type I fimbriae $($ fim $\mathrm{H})(13)$, antigen 43 (flu) (14), curly structural gene (csgA) (7), curly regulator gene $(\mathrm{crl})(15)$, meningitis-associated and temperature regulated fimbriae (mat), iron-regulated-gene-homologue adhesion (iha); ii) invasins: pathogenicity island-associated and meningitis-associated (gimB) (9), brain microvascular endothelium cell invasion (ibeA) (9), and toxigenic invasion locus in enterotoxigenic E. coli strains (tia) (9), and iii) K1 capsular polysaccharide (neuC) (16). The PCR amplifications were performed using a GeneAmp PCR System 2400 thermocycler (Applied Biosystems, USA) under the following conditions: denaturation for $5 \mathrm{~min}$ at $94^{\circ} \mathrm{C}, 30$ cycles of 60 $\mathrm{s}$ at $94^{\circ} \mathrm{C}, 30 \mathrm{~s}$ at the annealing temperature and $60 \mathrm{~s}$ at $72^{\circ} \mathrm{C}$, and a final extension step of $7 \mathrm{~min}$ at $72^{\circ} \mathrm{C}$.

\section{Adhesion and invasion assays}

Qualitative adhesion assays. Monolayers of $10^{5}$ Vero cells (African green monkey kidney cells) obtained from the American Type Culture Collection (ATCC, USA) were grown on coverslips (Falcon Becton Dickinson, USA) in 24-well plates in Dulbecco's modified Eagle's medium (DMEM) (Gibco-BRL, USA) containing 10\% fetal bovine serum (FBS). The bacteria were grown in $3 \mathrm{~mL}$ trypticase soy broth for $18 \mathrm{~h}$ at $37^{\circ} \mathrm{C}$. Vero cell monolayers were subsequently inoculated with approximately $3 \times 10^{8}$ bacteria/ $\mathrm{mL}$ (tube 1 on the MacFarland scale) and incubated at $37^{\circ} \mathrm{C}$ for $3 \mathrm{~h}(17)$. All assays were performed in duplicate on different days, with or without D-mannose in the medium. We analyzed 49 SEPEC strains and used E. coli C600 as a negative control.
After $3 \mathrm{~h}$ of infection, each well was washed with PBS, and $0.1 \%$ Triton $X-100$ was added for $5 \mathrm{~min}$. The coverslips were washed again, and $10 \mu \mathrm{g} / \mathrm{mL}$ phalloidin was added to each coverslip for $30 \mathrm{~min}$ in the absence of light. Following this incubation, the coverslips were washed and treated with $100 \mu \mathrm{g} / \mathrm{mL}$ RNase for $10 \mathrm{~min}$. Propidium iodide was then added to the coverslips at $1.7 \mu \mathrm{M}$ for $5 \mathrm{~min}$. The coverslips were then analyzed by microscopy.

\section{Scanning electron microscopy}

An ultrastructural analysis using SEM was performed on four SEPEC strains (SEPEC 8, 17, 19, and 53). After $3 \mathrm{~h}$ of infection, Vero cells were fixed with $2 \%$ paraformaldehyde (Sigma, USA) and $2 \%$ glutaraldehyde (Electron Microscope Science, USA) in $10 \mathrm{mM}$ cacodylate buffer, $\mathrm{pH}$ 7.4, mixed with equal volumes of cell culture medium. Subsequently, the slides were dehydrated with ethanol and immersed in propylene oxide/Epon 812 (Electron Microscope Science; ratios of $1: 1$ and $3: 1)$ for $6 \mathrm{~h}$. Ultrathin sections were obtained using an ultramicrotome and double-stained with $2 \%$ uranyl acetate (Fluka, Switzerland) and $0.5 \%$ lead citrate (Fluka). Finally, these sections were analyzed using a LEO-Schot Zeiss EM906 TEM at $80 \mathrm{kV}$.

Quantitative invasion assays. The bacterial invasion of Vero cells was measured using gentamycin protection assays and the enumeration of the colonies of viable intracellular bacteria (18). Prior to this assay, the minimal bactericidal concentration of gentamycin that reduced bacterial isolate counts by up to $99.9 \%$ was determined in DMEM, and gentamycin was first tested at 50 and $100 \mu \mathrm{g} /$ $\mathrm{mL}$. Because similar results were obtained independent of gentamycin concentration, a final gentamycin concentration of $100 \mu \mathrm{g} / \mathrm{mL}$ was used in subsequent experiments. After $3 \mathrm{~h}$ of infection, the cell monolayers were washed with PBS, and $1.0 \mathrm{~mL}$ DMEM plus $2.0 \% \mathrm{FBS}$ and $100 \mu \mathrm{g} / \mathrm{mL}$ gentamycin was added to each well to kill the extracellular bacteria. The plates were incubated for $2 \mathrm{~h}$ at $37^{\circ} \mathrm{C}$ before being washed ten times with $1 \mathrm{~mL}$ PBS per well. The intracellular bacteria were recovered by cell lysis with Triton $\mathrm{X}-100(1.0 \%)$, and bacterial cell invasion was determined based on the number of colony-forming units $(\mathrm{CFU} / \mathrm{mL})$ on MacConkey agar plates (19). All assays were performed in duplicate on two different days, with or without D-mannose in the medium. Our results were compared to a positive control (enteroinvasive E. coli (EIEC) serotype O124:H-) (18) and a negative control (E. coli C600).

Transmission electron microscopy. TEM analyses were performed on four SEPEC strains (SEPEC 8, 17, 19, and 53). After $3 \mathrm{~h}$ of infection, Vero cell monolayers were fixed with $2.5 \%$ glutaraldehyde, $4 \%$ paraformaldehyde and 10 $\mathrm{mM}$ calcium chloride in $100 \mathrm{mM}$ cacodylate buffer, $\mathrm{pH} 7.4$, for $1 \mathrm{~h}$ at $25^{\circ} \mathrm{C}$. Next, the cells were washed in cacodylate buffer and post-fixed with $1 \%$ osmium tetroxide $\left(\mathrm{OsO}_{4}\right)$ and $0.8 \% \mathrm{~K}_{4} \mathrm{Fe}(\mathrm{CN})_{6} \cdot 3 \mathrm{H}_{2} \mathrm{O}$ in $100 \mathrm{mM}$ cacodylate buffer for 1 h. The samples were then washed in cacodylate buffer, 
dehydrated in a graded series of alcohol, and embedded in Spurr resin. Ultrathin sections were obtained, stained with uranyl acetate and lead citrate, and examined using a Jeol 1200 EX TEM.

\section{Results and Discussion}

Studies demonstrating the adhesion and invasiveness of human SEPEC strains are rare (10). In contrast to diarrheagenic E. coli, UPEC and NMEC, SEPEC strains do not exhibit a well-defined molecular virulence profile $(10,12)$, and their pathogenicity mechanisms are not clear (4). SEPEC has emerged as a distinct $E$. coli group that appears to display a combination of the virulence characteristics of the other $E$. coli groups, including diarrheagenic E. coli and other ExPEC groups $(4,10)$. In the present study, we analyzed the bacterial adhesion and invasion properties of SEPEC strains involved in 49 cases of human sepsis at the University Hospital of the State University of Campinas, Brazil. All of these studies were performed using Vero cells to represent the urinary tract because the kidneys could be an entry point of SEPEC into the bloodstream. The three-dimensional (3-D) architecture of the extracellular matrix of SEPEC isolates undergoing adhesion was also examined, and the invasion process was visualized using TEM. Vero cells are not derived from tumors and are an analogous model for studying SEPEC infections in renal cells, as previously published (10).

Currently, the mechanisms by which $E$. coli attaches to surfaces are not well defined. However, some cellular and extracellular structures, such as flagella, type I fimbriae, antigen 43, curli fimbriae and exopolysaccharides (EPS), are fundamental in establishing $E$. coli adhesion (20-22). Flagella are important for the initial interaction with and the movement of $E$. colialong surfaces (21), and type I fimbriae are required for the initial adhesion of $E$. coli to substrates (21). Both antigen 43, an outer membrane protein, and curli fimbriae play important roles in auto-aggregation, increased adhesion (23) and the persistence of bacteria on live tissues $(24,25)$. Additionally, EPS produced by adhered bacteria builds extracellular matrices that are responsible for the formation of 3-D micro-colonies and $E$. coli persistence on different substrates (21).

In our study, the genotypic analysis of virulence factor genes showed a high prevalence of adhesin-encoding genes, with 48 isolates testing positive for fim $\mathrm{H}(98.0 \%)$, 34 for flu (69.4\%), 26 for csgA (53.1\%), 19 for mat (38.8\%), and 16 for iha $(32.7 \%)$. However, a low prevalence of invasin-encoding genes was observed, and only 8 isolates were positive for tia (16.3\%), 6 for gimB (12.3\%) and 5 for ibeA (10.2\%) (Table 1). The neuC gene, which encodes K1 capsular polysaccharide, was amplified from only $24.5 \%$ of the strains. Because epidemiological studies have linked K1 to $\operatorname{NMEC}(26,27)$, these data suggest a genetic relationship between some SEPEC and NMEC isolates.
Data demonstrating the high prevalence of adhesin genes and the low prevalence of invasin genes in SEPEC strains are consistent with the literature (10), suggesting that SEPEC most likely adheres to cell surfaces by mechanisms different from those of other E. coli strains. Additionally, it is likely that SEPEC strains may express several other adhesion factors that are not yet known to be involved in their pathogenicity; these factors may also play a role in tissue specificity and the adhesion of SEPEC to epithelial and endothelial cells (data not shown).

For further adhesion and invasion assays, we analyzed four SEPEC strains using fluorescence microscopy, SEM and TEM. The strains chosen were SEPEC $8\left(\mathrm{fimH}^{+} / f l^{+}\right)$, SEPEC $17\left(\mathrm{fimH}^{+} / \mathrm{flu}^{+} /\right.$iha $\left.^{+} / \operatorname{gimB}^{+}\right)$, SEPEC $19\left(\mathrm{fimH}^{+} /\right.$ $\left.\operatorname{gim} \mathrm{B}^{+}\right)$, and SEPEC $53\left(\mathrm{fimH}^{+} / \mathrm{fl} / \mathrm{u}^{+} / \mathrm{csg} \mathrm{A}^{+}\right)$.

SEPEC adhesion was observed using a fluorescence assay, as shown in Figure 1.

SEM revealed the formation of microcolonies surrounded by an extracellular matrix when SEPEC strains adhered to Vero cells (Figures 2 and 3). Studies have shown that adhesion is crucial for the establishment of E. coli-associated extraintestinal infections (28), such as urinary tract infections (29). In particular, bacterial adhesion is important in establishing chronic cystitis and bloodstream infections associated with catheters (3). However, there are no consistent data on SEPEC adhesion to cell surfaces.

Overall, $98 \%$ of SEPEC strains were fimH-positive. Although type I fimbriae are important fimbriae used by UPEC to adhere to and invade bladder cells $(13,29,30)$, the role of type I fimbriae in virulence is not as well defined as in other E. coli groups. However, because UPEC, SEPEC and other ExPEC groups share many virulence factors, $f i m \mathrm{H}$ most likely has a similar function in SEPEC in the urinary environment. Thus, adhesion and invasion assays were performed in the presence of D-mannose. All SEPEC isolates (100\%) adhered to and invaded cells in the presence of D-mannose (data not shown). Our invasion results were compared to those obtained for a positive control, and four SEPEC strains were subsequently chosen for ultrastructural analyses using SEM and TEM (Figure 4).

Using TEM, we observed that the bacteria adhered to many points on the cell surface, and we observed individual intracellular bacteria after $3 \mathrm{~h}$ of incubation with Vero cells in the presence or absence of D-mannose (Figure 5A). Additionally, bacterial subpopulations were observed, suggesting the presence of intracellular bacterial replication (Figure $5 B$ ).

Thus, SEPEC strains adhered to Vero cells, formed microcolonies, produced an extracellular matrix, invaded cells, and probably replicated inside Vero cells. These findings suggest the occurrence of two simultaneous yet independent events. In fact, the adhesion to and invasion of Vero cells by SEPEC strains can be important factors involved in their pathogenicity, and these results may suggest one of the possible steps of SEPEC entry into kidney blood vessels. 
Table 1. Genotypic analysis of human sepsis-associated Escherichia coli (SEPEC) strains.

\begin{tabular}{|c|c|c|c|c|c|c|c|c|c|c|}
\hline \multirow[t]{2}{*}{ No. SEPEC strain } & \multirow{2}{*}{$\frac{\mathrm{K} 1 \text { capsular polysaccharide }}{\text { neuC }}$} & \multicolumn{6}{|c|}{ Adhesins } & \multicolumn{3}{|c|}{ Invasins } \\
\hline & & fim $\mathrm{H}$ & flu & $\operatorname{csg} \mathrm{A}$ & $\mathrm{crl}$ & mat & iha & $\operatorname{gim} \mathrm{B}$ & $i b e A$ & tia \\
\hline 3 & - & + & - & - & + & - & - & - & - & + \\
\hline 4 & - & + & + & - & + & - & + & - & - & - \\
\hline 5 & + & + & - & - & + & - & - & - & - & + \\
\hline 8 & - & + & + & - & + & - & - & - & - & - \\
\hline 10 & - & + & - & + & + & + & - & + & + & - \\
\hline 13 & - & + & + & - & + & - & + & - & - & - \\
\hline 14 & - & + & + & - & + & + & - & - & + & - \\
\hline 16 & - & + & + & - & + & + & + & - & + & - \\
\hline 17 & - & + & + & - & + & - & + & + & - & - \\
\hline 18 & - & + & + & + & + & - & + & + & - & - \\
\hline 19 & - & + & - & - & + & - & - & + & - & - \\
\hline 20 & - & + & + & + & + & - & - & - & - & - \\
\hline 21 & - & + & + & + & + & - & - & - & - & - \\
\hline 22 & - & + & + & - & + & - & + & - & - & - \\
\hline 23 & - & + & - & + & + & + & - & - & + & - \\
\hline 24 & - & + & - & + & + & + & - & + & - & - \\
\hline 25 & - & - & + & - & + & + & + & - & + & - \\
\hline 26 & - & + & - & + & + & + & - & - & - & - \\
\hline 27 & + & + & + & - & + & - & - & - & - & - \\
\hline 28 & + & + & + & - & + & + & - & - & - & - \\
\hline 29 & + & + & - & - & + & - & - & - & - & - \\
\hline 31 & - & + & + & + & + & + & - & - & - & - \\
\hline 33 & - & + & + & + & + & - & - & - & - & - \\
\hline 34 & + & + & + & - & + & + & + & - & - & + \\
\hline 36 & + & + & + & + & + & - & - & - & - & - \\
\hline 37 & + & + & + & + & + & + & - & - & - & - \\
\hline 38 & - & + & + & - & + & - & + & - & - & + \\
\hline 39 & - & + & + & + & + & + & - & - & - & - \\
\hline 40 & - & + & + & + & + & - & - & - & - & - \\
\hline 41 & - & + & + & + & + & + & + & - & - & - \\
\hline 42 & - & + & + & + & + & - & - & - & - & - \\
\hline 43 & - & + & - & + & + & + & - & - & - & - \\
\hline 44 & - & + & - & - & - & - & - & - & - & - \\
\hline 46 & - & + & + & + & - & - & - & - & - & - \\
\hline 47 & + & + & - & - & + & - & - & - & - & - \\
\hline 48 & - & + & + & + & + & + & + & - & - & - \\
\hline 49 & + & + & + & + & + & - & - & - & - & + \\
\hline 50 & + & + & + & + & + & + & - & + & - & + \\
\hline 51 & + & + & + & - & + & - & - & - & - & + \\
\hline 52 & - & + & - & + & + & + & - & - & - & - \\
\hline 53 & - & + & + & + & + & - & - & - & - & - \\
\hline 54 & + & + & + & + & + & - & + & - & - & + \\
\hline 56 & - & + & + & + & + & + & + & - & - & - \\
\hline 57 & - & + & - & - & + & - & + & - & - & - \\
\hline 58 & - & + & + & + & + & - & + & - & - & - \\
\hline 62 & - & + & + & + & + & + & + & - & - & - \\
\hline 71 & - & + & - & - & + & - & - & - & - & - \\
\hline 74 & - & + & - & - & + & - & - & - & - & - \\
\hline 76 & - & + & + & - & + & - & - & - & - & - \\
\hline
\end{tabular}



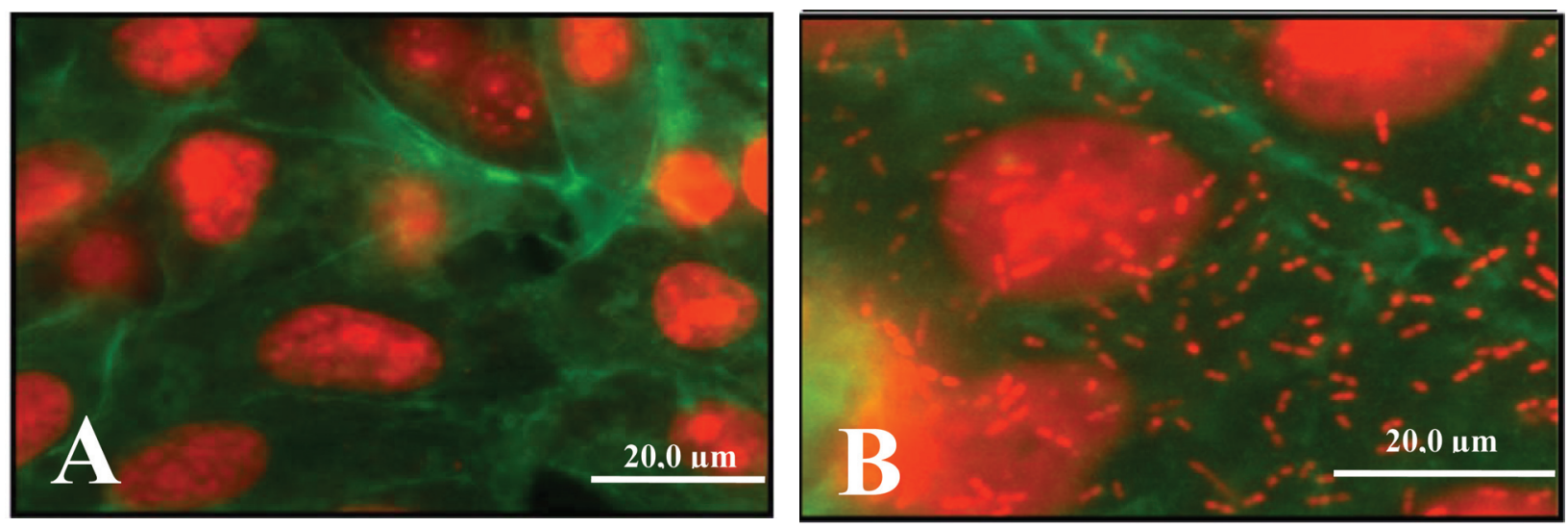

Figure 1. The adhesion of human sepsis-associated Escherichia coli (SEPEC) strains to Vero cells was observed using a fluores-

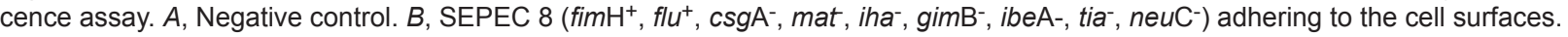
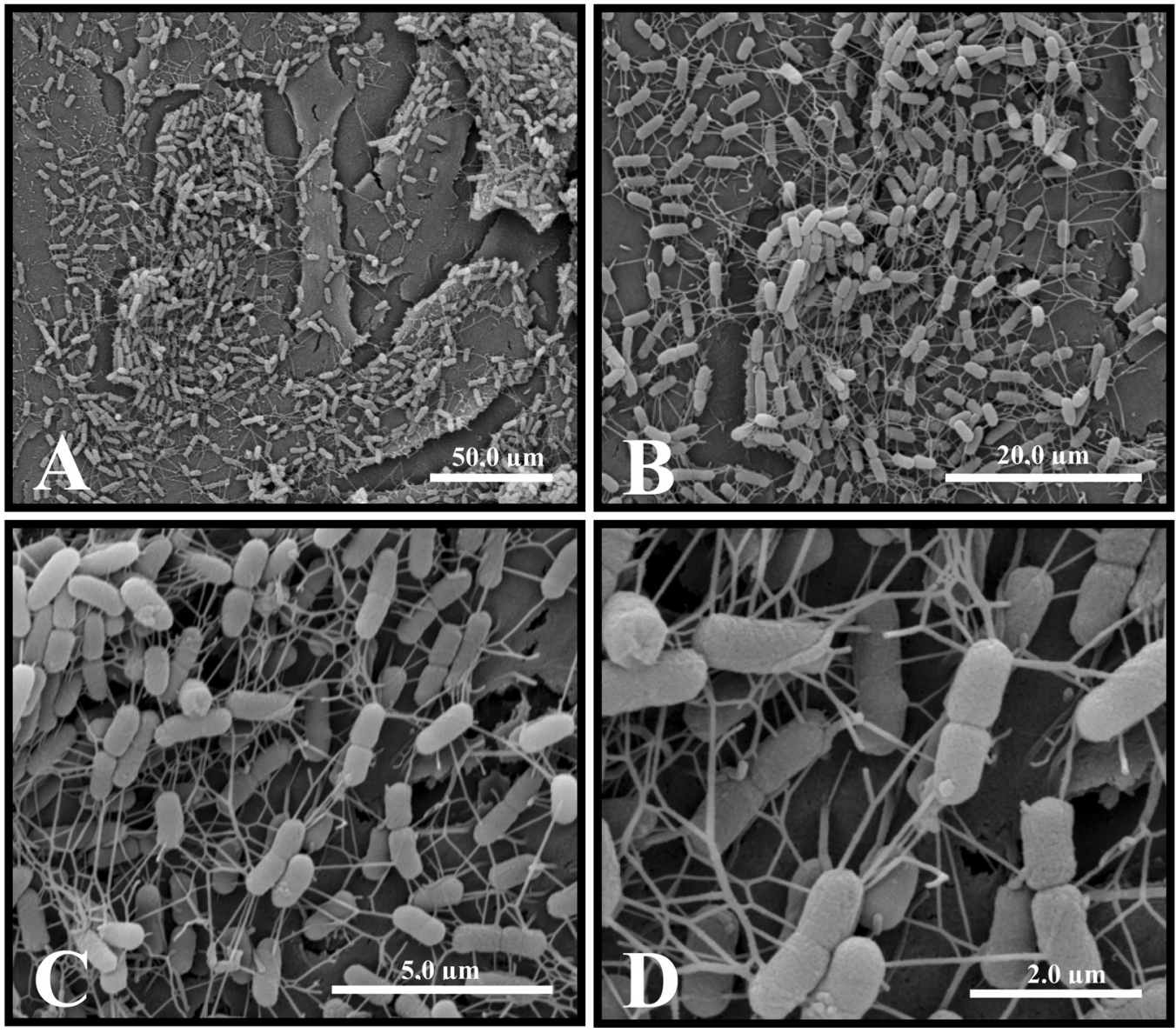

Figure 2. Scanning electron micrograph of human sepsis-associated Escherichia coli (SEPEC) 8 (fim $\mathrm{H}^{+}$, flu ${ }^{+}$,

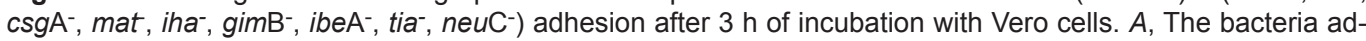
hered to the cell surface. $B$, Details of the points of microcolony formation. $C$, Microcolony details. $D$, Details of the network of extracellular matrix surrounding the microcolonies on the cell surface. 

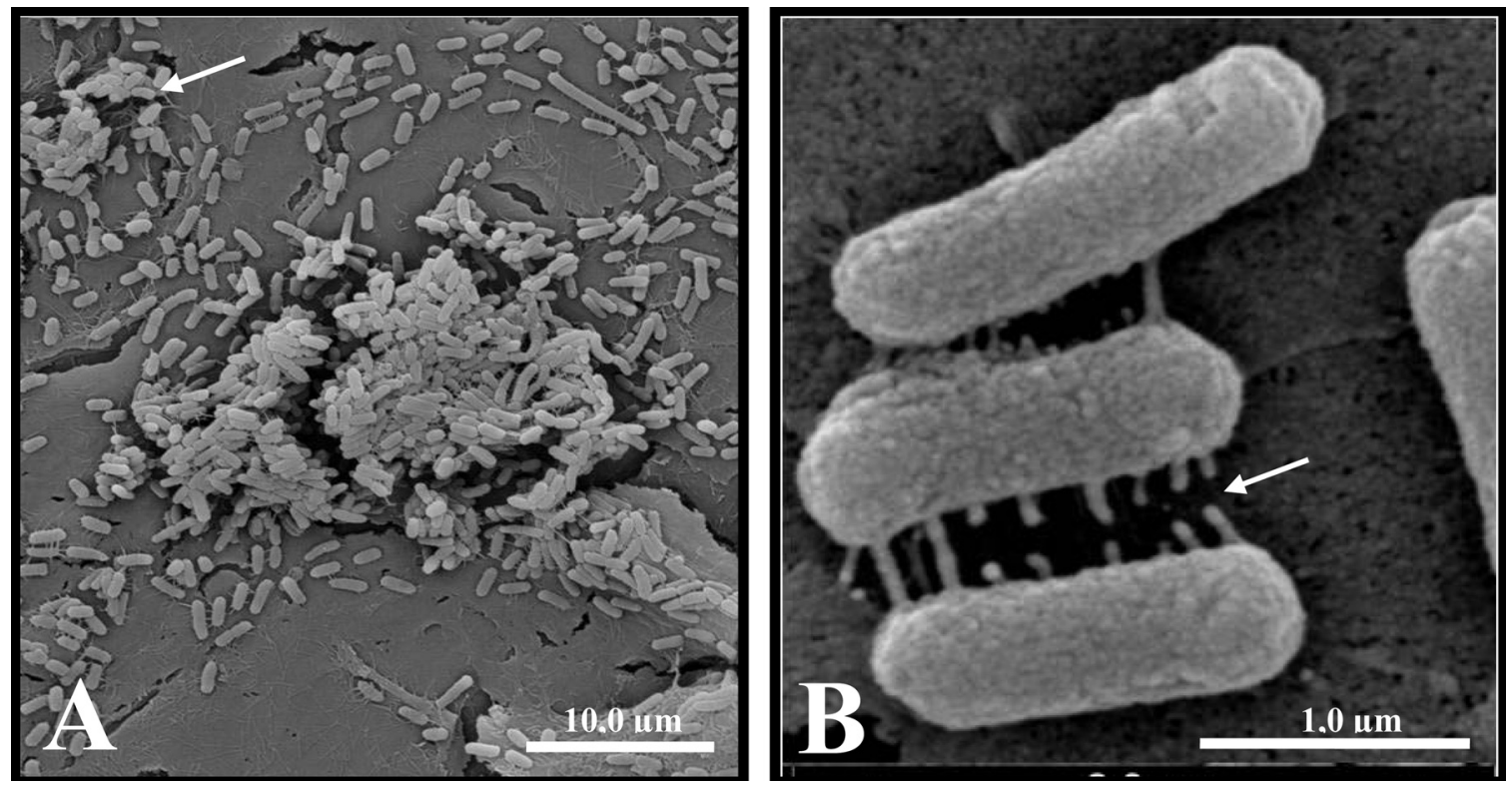

Figure 3. Scanning electron micrograph of human sepsis-associated Escherichia coli (SEPEC) $8\left(f i m \mathrm{H}^{+}, f u^{+}, \operatorname{csgA} \mathrm{A}^{-}, \mathrm{mat}\right.$,

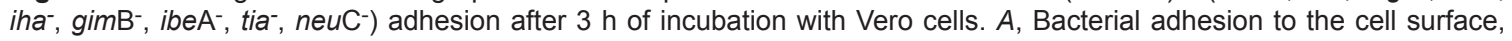
with the formation of microcolonies surrounded by extracellular matrix (arrow). B, Early extracellular matrix production by bacteria adhered to the cell surface (arrow).

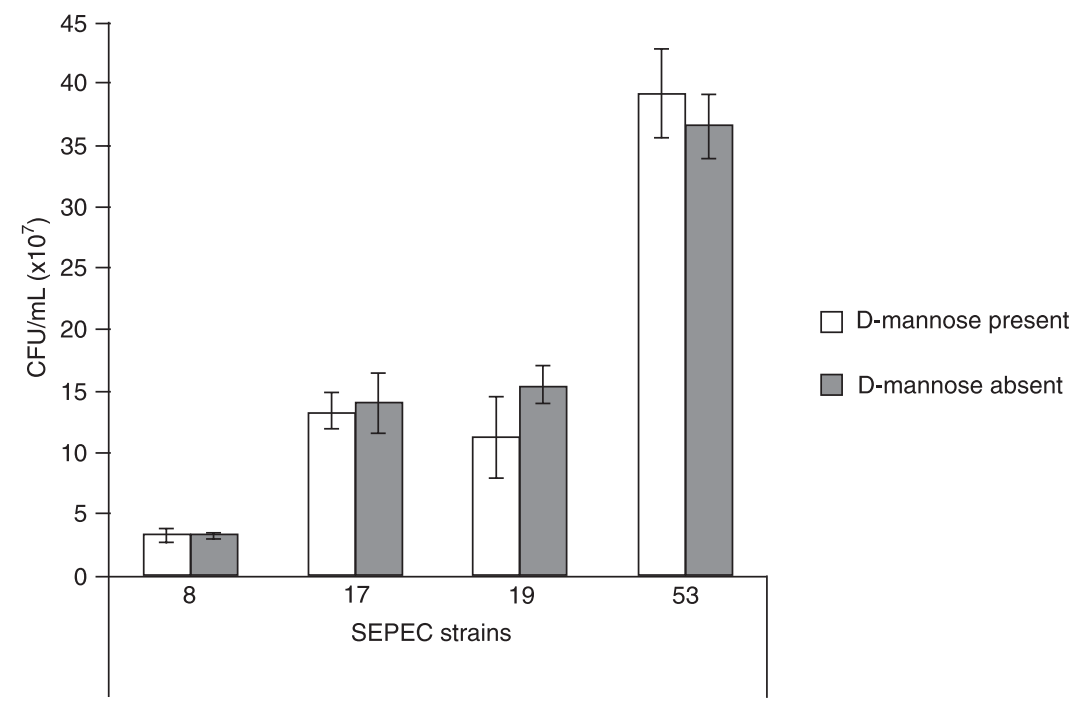

Figure 4. Colony-forming units $(\mathrm{CFU} / \mathrm{mL})$ of the human sepsis-associated Escherichia coli (SEPEC) strains chosen for transmission electron microscopy and scanning electron microscopy that were recovered from the intracellular environment. All 49 strains were recovered at higher concentrations (up to $2 \times 10^{7} \mathrm{CFU} / \mathrm{mL}$ ) than the positive control (EIEC O124:H) in the presence or absence of D-mannose in the medium. The negative control, E. coli $\mathrm{C} 600$, did not invade Vero cells. 

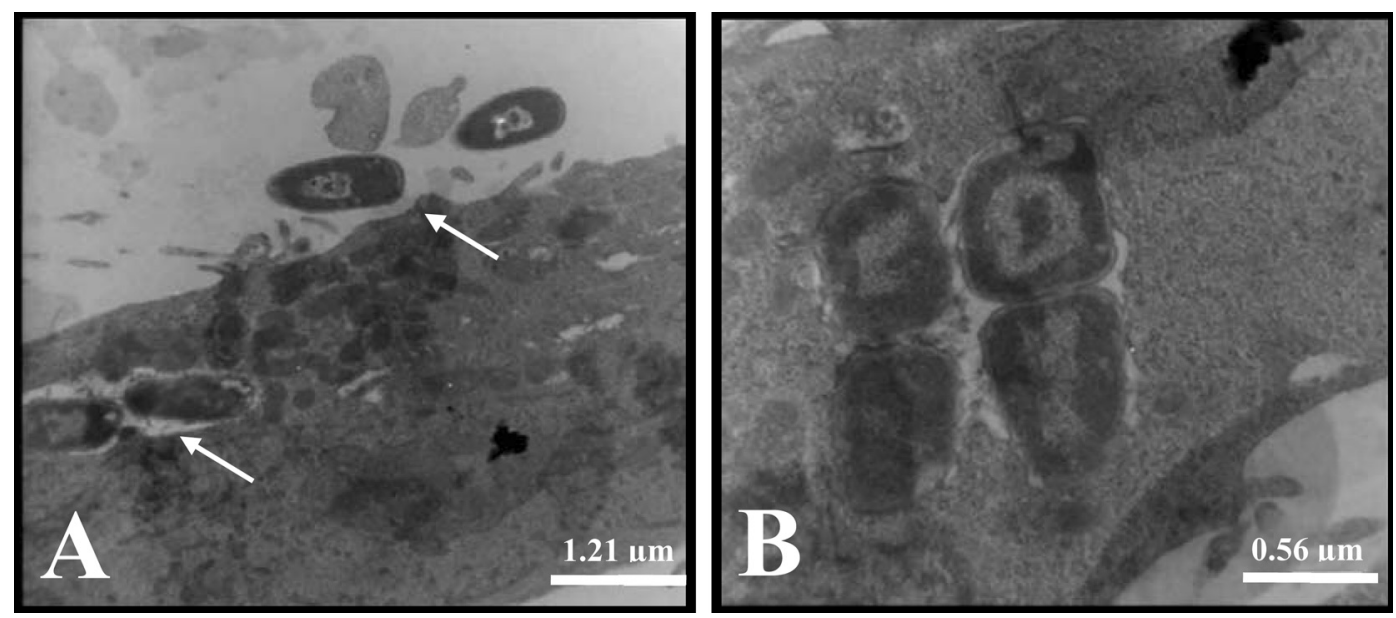

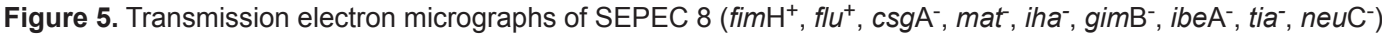
adhesion and invasion after $3 \mathrm{~h}$ of incubation with Vero cells in the presence or absence of D-mannose. $A$, Bacteria that adhered to the cell surface (arrow) and intracellular bacteria in the absence of D-mannose. $B, A$ group of four bacteria that suggests intracellular bacterial replication in the absence of D-mannose.

Extraintestinal infections caused by $E$. coli, such as urinary infections, are common causes of bacteremia $(3,30)$, a condition that always precedes sepsis. Therefore, SEPEC adhesion to host tissues, such as the kidney, could be an important factor in the course of sepsis by providing an entrance to the bloodstream. Once in the bloodstream, SEPEC strains must have favorable genetic compositions to survive in the blood and, in this way, induce sepsis (10). Some investigators have described the importance of fim $\mathrm{H}$ (31-33), ag43 $(34,35)$ and $\operatorname{csg} \mathrm{A}(25)$ in urinary tract and meninges infections. In addition, csgA has been shown to contribute to coagulation and blood pressure abnormalities, thereby contributing to SEPEC-induced septic shock (7).

The mechanisms by which SEPEC adhere to and invade Vero cells are not clear. However, these mechanisms suggest a gateway for SEPEC entry into the bloodstream during the course of sepsis. Although the adhesion to and invasion of eukaryotic cells by other ExPEC groups have been previously described $(28,32)$, our data detail these processes for SEPEC clinical isolates and suggest a possible mechanism for SEPEC entry into blood vessels. We will continue searching for the factors involved in SEPEC adhesion and the relationship of these factors to the development of human sepsis. Currently, we are conducting proteomic analyses of the adhesion and invasion factors that are related to SEPEC adhesion to Vero cells to further elucidate the mechanisms involved in human sepsis.

\section{Acknowledgments}

We thank Dr. Luciano Moura Martins (Instituto Adolfo Lutz, São Paulo, SP, Brasil) and Robert Alvin Bernedo Navarro (Universidade Estadual de Campinas, Campinas, SP, Brasil) for scientific support and Ana Stella Menegon Degrossoli (Universidade Estadual de Campinas) for technical assistance. Research supported by CAPES.

\section{References}

1. Eisenstein $\mathrm{BI}$, Jones $\mathrm{GW}$. The spectrum of infections and pathogenic mechanisms of Escherichia coli. Adv Intern Med 1988; 33: 231-252

2. Kaper JB, Nataro JP, Mobley HL. Pathogenic Escherichia coli. Nat Rev Microbiol 2004; 2: 123-140.

3. Martinez JA, Soto S, Fabrega A, Almela M, Mensa J, Soriano $A$, et al. Relationship of phylogenetic background, biofilm production, and time to detection of growth in blood culture vials with clinical variables and prognosis associated with Escherichia coli bacteremia. J Clin Microbiol 2006; 44: 14681474.

4. Mokady D, Gophna U, Ron EZ. Virulence factors of septice-

mic Escherichia coli strains. Int J Med Microbiol 2005; 295: 455-462.

5. Selander RK, Caugant DA, Whittam TS. Genetic structure and variation in natural populations of Escherichia coli. In: Neidhardt FC, Ingraham KL, Magasanik B, Low KB, Schaechter M, Umbarger HE (Editors), Escherichia coli and Salmonella typhimurium: cellular and molecular biology. Washington: an Society for Microbiology; 1987. p 16251648.

6. Selander RK, Korhonen TK, Vaisanen-Rhen V, Williams PH, Pattison PE, Caugant DA. Genetic relationships and clonal structure of strains of Escherichia coli causing neonatal sep- 
ticemia and meningitis. Infect Immun 1986; 52: 213-222.

7. Bian Z, Brauner A, Li Y, Normark S. Expression of and cytokine activation by Escherichia coli curli fibers in human sepsis. J Infect Dis 2000; 181: 602-612.

8. McBean M, Rajamani S. Increasing rates of hospitalization due to septicemia in the US elderly population, 1986-1997. $J$ Infect Dis 2001; 183: 596-603.

9. Ewers C, Li G, Wilking H, Kiessling S, Alt K, Antao EM, et al. Avian pathogenic, uropathogenic, and newborn meningitiscausing Escherichia coli: how closely related are they? Int $J$ Med Microbiol 2007; 297: 163-176.

10. Ananias M, Yano T. Serogroups and virulence genotypes of Escherichia coli isolated from patients with sepsis. Braz J Med Biol Res 2008; 41: 877-883.

11. Hall-Stoodley L, Costerton JW, Stoodley P. Bacterial biofilms: from the natural environment to infectious diseases. Nat Rev Microbiol 2004; 2: 95-108.

12. Croxen MA, Finlay BB. Molecular mechanisms of Escherichia coli pathogenicity. Nat Rev Microbiol 2010; 8: 26-38.

13. Johnson JR, Russo TA, Tarr PI, Carlino U, Bilge SS, Vary $\mathrm{JC} \mathrm{Jr}$, et al. Molecular epidemiological and phylogenetic associations of two novel putative virulence genes, iha and iroN (E. coli), among Escherichia coli isolates from patients with urosepsis. Infect Immun 2000; 68: 3040-3047.

14. Yang HH, Vinopal RT, Grasso D, Smets BF. High diversity among environmental Escherichia coli isolates from a bovine feedlot. Appl Environ Microbiol 2004; 70: 1528-1536.

15. Maurer JJ, Brown TP, Steffens WL, Thayer SG. The occurrence of ambient temperature-regulated adhesins, curli, and the temperature-sensitive hemagglutinin tsh among avian Escherichia coli. Avian Dis 1998; 42: 106-118.

16. Watt $S$, Lanotte $P$, Mereghetti L, Moulin-Schouleur M, Picard B, Quentin R. Escherichia coli strains from pregnant women and neonates: intraspecies genetic distribution and prevalence of virulence factors. J Clin Microbiol 2003; 41: 1929-1935.

17. Scaletsky IC, Silva ML, Trabulsi LR. Distinctive patterns of adherence of enteropathogenic Escherichia coli to HeLa cells. Infect Immun 1984; 45: 534-536.

18. Peerbooms PG, Verweij AM, Maclaren DM. Vero cell invasiveness of Proteus mirabilis. Infect Immun 1984; 43: 10681071.

19. Barbosa HR, Rodrigues MFA, Campos CC, Chaves ME, Nunes I, Juliano Y, et al. Counting of viable cluster-forming and non cluster-forming bacteria: a comparison between the drop and the spread methods. Methods 1995; 22: 39-50.

20. Costerton JW, Stewart PS, Greenberg EP. Bacterial biofilms: a common cause of persistent infections. Science 1999; 284: 1318-1322.

21. Danese PN, Pratt LA, Dove SL, Kolter R. The outer membrane protein, antigen 43, mediates cell-to-cell interactions within Escherichia coli biofilms. Mol Microbiol 2000; 37: 424-432.
22. Pratt LA, Kolter R. Genetic analysis of Escherichia coli biofilm formation: roles of flagella, motility, chemotaxis and type I pili. Mol Microbiol 1998; 30: 285-293.

23. Hasman H, Chakraborty T, Klemm P. Antigen-43-mediated autoaggregation of Escherichia coli is blocked by fimbriation. J Bacteriol 1999; 181: 4834-4841.

24. Gophna U, Barlev M, Seijffers R, Oelschlager TA, Hacker J, Ron EZ. Curli fibers mediate internalization of Escherichia coli by eukaryotic cells. Infect Immun 2001; 69: 2659-2665.

25. Kikuchi T, Mizunoe Y, Takade A, Naito S, Yoshida S. Curli fibers are required for development of biofilm architecture in Escherichia coli K-12 and enhance bacterial adherence to human uroepithelial cells. Microbiol Immunol 2005; 49: 875-884.

26. Achtman M, Heuzenroeder M, Kusecek B, Ochman H, Caugant D, Selander RK, et al. Clonal analysis of Escherichia coli $\mathrm{O} 2: \mathrm{K} 1$ isolated from diseased humans and animals. Infect Immun 1986; 51: 268-276.

27. Kim KS, Itabashi H, Gemski P, Sadoff J, Warren RL, Cross AS. The K1 capsule is the critical determinant in the development of Escherichia coli meningitis in the rat. $J$ Clin Invest 1992; 90: 897-905.

28. Ramírez RM, Almanza Y. Adherence and invasion of avian pathogenic Escherichia coli to avian tracheal epithelial cells. W J Microbiol Biotech 2009; 25: 1019-1023.

29. Tiba MR, Yano T, Leite DS. Genotypic characterization of virulence factors in Escherichia coli strains from patients with cystitis. Rev Inst Med Trop São Paulo 2008; 50: 255-260.

30. Rijavec M, Muller-Premru M, Zakotnik B, Zgur-Bertok D. Virulence factors and biofilm production among Escherichia coli strains causing bacteraemia of urinary tract origin. $J$ Med Microbiol 2008; 57: 1329-1334.

31. Connell I, Agace W, Klemm P, Schembri M, Marild S, Svanborg C. Type 1 fimbrial expression enhances Escherichia coli virulence for the urinary tract. Proc Natl Acad Sci U S A 1996; 93: 9827-9832.

32. Kau AL, Hunstad DA, Hultgren SJ. Interaction of uropathogenic Escherichia coli with host uroepithelium. Curr Opin Microbiol 2005; 8: 54-59.

33. Pouttu R, Puustinen T, Virkola R, Hacker J, Klemm P, Korhonen TK. Amino acid residue Ala-62 in the FimH fimbrial adhesin is critical for the adhesiveness of meningitis-associated Escherichia coli to collagens. Mol Microbiol 1999; 31: 1747-1757.

34. Kjaergaard K, Schembri MA, Hasman H, Klemm P. Antigen 43 from Escherichia coli induces inter- and intraspecies cell aggregation and changes in colony morphology of Pseudomonas fluorescens. J Bacteriol 2000; 182: 47894796.

35. Ulett GC, Mabbett AN, Fung KC, Webb RI, Schembri MA. The role of F9 fimbriae of uropathogenic Escherichia coli in biofilm formation. Microbiology 2007; 153: 2321-2331. 